\title{
Association Between Child Poverty and Academic Achievement
}

\section{Citation}

Oulhote, Youssef, and Philippe Grandjean. 2016. “Association Between Child Poverty and Academic Achievement." JAMA Pediatrics 170 (2) (February 1): 179. doi:10.1001/ jamapediatrics.2015.3856.

\section{Published Version}

doi:10.1001/jamapediatrics.2015.3856

\section{Permanent link}

http://nrs.harvard.edu/urn-3:HUL.InstRepos:34787291

\section{Terms of Use}

This article was downloaded from Harvard University's DASH repository, and is made available under the terms and conditions applicable to Other Posted Material, as set forth at http:// nrs.harvard.edu/urn-3:HUL.InstRepos:dash.current.terms-of-use\#LAA

\section{Share Your Story}

The Harvard community has made this article openly available.

Please share how this access benefits you. Submit a story.

\section{Accessibility}


more than 3 decades, addressed the many variables of at-risk children: "Recent research has demonstrated quite convincingly that family structure is strongly associated with children's well-being, even in the very generous Nordic welfare states...children living with single mothers had fewer material resources, less parental support, and poorer health than those living with 2 original parents." 3 Poverty of relationships may be the strongest predictor of behavioral and academic deficiencies.

The Centers for Disease Control and Prevention-National Health Interview Survey publication, "Family Structure and Children's Health in the United States," reports on 249570 families regarding both medical and behavioral health concerns. Among the findings: "Children in nuclear families were generally less likely than children in their remaining family types to have a learning disability or ADHD [attention-deficit/ hyperactivity disorder] regardless of parent's education, income, poverty status, place of residence, or region."4(p62)

Finally, as noted in the editorial by Luby, ${ }^{2}$ as well as the JAMA Pediatrics article by Bick et al, ${ }^{5}$ child brains grow when loved and nurtured. The research by Bick et $\mathrm{al}^{5}$ demonstrates that enhanced brain development is consistent with the relationship wealth of a nuclear family.

Findings from Child Trends, the Search Institute, and the National Institutes of Health Add Health demonstrate that relationships are better predictors of development than money. The JAMA Network should avoid the appearance of 2-dimensional analysis that implies causality without addressing all variables. It would be deeply regrettable if the conclusions from the article actually led to more discrimination by associating children with lower socioeconomic status with poor brain development and achievement.

This very important topic should not fuel unbalanced advocacy for the children it intends to serve. These children, like their great-grandfathers, have the capacity to become great through caring, competent, and resilient families. Let us advocate for stable families as well as funds.

\section{Alma L. Golden, MD}

Author Affiliation: retired, Department of Pediatrics, Texas A\&M Health Science Center, Temple.

Corresponding Author: Alma L. Golden, MD, Department of Pediatrics, Texas A\&M Health Science Center, 4102 Burton Ln, Temple, TX 76502 (almaleila@hotmail.com).

Published Online: December 28, 2015. doi:10.1001/jamapediatrics.2015.3853.

Conflict of Interest Disclosures: None reported.

1. Hair NL, Hanson JL, Wolfe BL, Pollak SD. Association of child poverty, brain development, and academic achievement. JAMA Pediatr. 2015;169(9):822-829.

2. Luby JL. Poverty's most insidious damage: the developing brain. JAMA Pediatr. 2015;169(9):810-811.

3. Thomson E, McLanahan SS. Reflections on "family structure and child well-being: economic resources vs parental socialization." Soc Forces. 2012;91 (1):45-53.

4. Blackwell DL; National Center for Health Statistics. Family structure and children's health in the united states: findings from the national health interview survey, 2001. Vital Health Stat 10. 2010(246):1-166.

5. Bick J, Zhu T, Stamoulis C, Fox NA, Zeanah C, Nelson CA. Effect of early institutionalization and foster care on long-term white matter development: a randomized clinical trial. JAMA Pediatr. 2015;169(3):211-219.

\section{Association Between Child Poverty and Academic Achievement}

To the Editor Hair et al $^{1}$ reported in the September 2015 issue of JAMA Pediatrics on the association between child poverty, brain development, and academic achievement. This study provided evidence that as much as $20 \%$ of povertyassociated achievement deficits may be a result of a maturation lag in the frontal lobe, the temporal lobe, and the hippocampus. The authors suggested that the results might underestimate the true effect of poverty on child development because they examined a relatively healthy sample of US children who, for the most part, differ only in terms of family income.

We argue that at least a part of the observed effects might be attributable to exposure to environmental neurotoxicants, rather than poverty as such. Children with a low socioeconomic background have been shown to be more exposed to environmental toxicants. ${ }^{2}$ In addition, some neurotoxicants are known to affect both academic achievement and induce structural brain changes similar to those reported in this study.,4 The authors prudently excluded children with low birth weights or attention problems and 3 children with previous lead poisoning in an attempt to identify the independent effect of poverty. However, neurotoxicants, such as lead and pesticides, may exert detrimental effects on gray matter volume and academic achievement at low exposure levels that may have occurred prenatally or early postnatally.

The authors acknowledged that a third factor may have played a role, such as genetic predisposition. However, pesticide exposure from nonorganic foods and lead exposure from poor housing are likely to confound the relationship between brain development and academic achievement on one hand, while mediating the poverty-achievement relationship on the other.

Data on legally mandated blood-lead screening could be useful to yield unbiased direct and indirect estimates. Adjusting for neurotoxicant exposure is necessary to prevent collider bias introduced by adjustment for the mediator (ie, brain development). On the other hand, such adjustment would likely bias the estimate of the direct effect downward by blocking the effect of poverty on academic achievement acting through the neurotoxicant path. In this scenario, methods based on a counterfactual framework, such as marginal structural models and g-formula estimation, are required to adjust for the confounding effect of neurotoxicant exposure without blocking the corresponding direct path from poverty to achievement. ${ }^{5}$

While the study by Hair et $\mathrm{al}^{1}$ is an important step toward understanding the importance of the poverty-achievement gap, further work is clearly needed to clarify the pathogenetic details of this link.

Youssef Oulhote, PhD Philippe Grandjean, MD, PhD

Author Affiliations: Department of Environmental Health, Harvard T. H. Chan School of Public Health, Boston, Massachusetts. 
Corresponding Author: Youssef Oulhote, PhD, Department of Environmenta Health, Harvard T. H. Chan School of Public Health, Landmark Center 3E, 401 Park Dr, Boston, MA 02215 (youlhote@hsph.harvard.edu).

Published Online: December 28, 2015. doi:10.1001/jamapediatrics.2015.3856. Conflict of Interest Disclosures: None reported.

1. Hair NL, Hanson JL, Wolfe BL, Pollak SD. Association of child poverty, brain development, and academic achievement. JAMA Pediatr. 2015;169(9):822-829.

2. Belova A, Greco SL, Riederer AM, Olsho LE, Corrales MA. A method to screen US environmental biomonitoring data for race/ethnicity and income-related disparity. Environ Health. 2013;12:114.

3. Cecil KM, Brubaker CJ, Adler CM, et al. Decreased brain volume in adults with childhood lead exposure. PLoS Med. 2008;5(5):e112.

4. Rauh VA, Perera FP, Horton MK, et al. Brain anomalies in children exposed prenatally to a common organophosphate pesticide. Proc Natl Acad Sci U S A. 2012;109(20):7871-7876.

5. Richiardi L, Bellocco R, Zugna D. Mediation analysis in epidemiology: methods, interpretation and bias. Int J Epidemiol. 2013;42(5):1511-1519.

In Reply We are delighted that our article ${ }^{1}$ has continued to increase interest in the ways that growing up in poor families affects children's health and development. We welcome the Letters to the Editor appearing in this issue of JAMA Pediatrics and concur that the experiences described by the authors are important components of impoverished environments. However, we are not as certain as the authors that any single factor irrefutably explains the results that we found.

Oulhote and Grandjean suggest that the association between childhood poverty, brain structure, and academic achievement could be explained by increased exposure to environmental toxins. Exposure to toxins, including neurotoxicants such as pesticides and lead, is a known and serious risk factor for children in poverty. However, in our article, ${ }^{1}$ we note that children were screened out for a history of lead poisoning along with a number of conditions indicative of elevated blood lead levels (eg, behavior and learning problems, hearing problems, low IQ, and growth failure). Still, the authors raise an important point; further examination of this potential pathway is warranted.

Dr Golden suggests that primary emphasis should be placed on the role of family instability. We agree that impaired caregiver-child relationships impede healthy child development. Indeed, many recent studies point to the deleterious effects of early adversity and stress on children's learning, behavior, and health. ${ }^{2}$

Both letters touch on the question that we are most often asked: "which aspect of poverty is causing these problems for children?" In addition to limited material resources, children living in poverty are likely to confront elevated levels of life stress, family instability, and violence; have poor nutrition; encounter less complex language and few books in the home; receive less consistent health care; live in crowded, noisy, or dangerous places that interfere with sleep; have more exposure to toxins; and attend underfunded schools. Meanwhile their caregivers are less likely to command the tools necessary to buffer children from the influences of these adverse early experiences.

Next steps should focus on the difficult task of elucidating which individual factor, or combination of factors, contributes to poverty's influence on health and development and understanding the precise biological mechanisms through which these experiences confer risk. Growing up in poverty entails numerous inequities that are difficult to disentangle. It is worth noting that we studied only the healthiest, most robust of the poor, yet we still found striking effects of poverty. Family income may itself be an important pathway.

Our data do not imply that the abilities and health of lowincome children are somehow predetermined or permanent. Rather, by studying areas of the brain that demonstrate plasticity, we can learn which causal factors tied to poverty influence children the most at various stages of development, and then design and test the effectiveness of interventions to improve children's well-being.

\section{Nicole L. Hair, PhD \\ Jamie L. Hanson, PhD \\ Barbara L. Wolfe, PhD Seth D. Pollak, PhD}

Author Affiliations: Department of Health Management and Policy, School of Public Health, University of Michigan, Ann Arbor (Hair); Department of Psychology and Neuroscience, Duke University, Durham, North Carolina (Hanson); Departments of Economics, Population Health Sciences, and Public Affairs, University of Wisconsin-Madison (Wolfe); Department of Psychology and Waisman Center, University of Wisconsin-Madison (Pollak).

Corresponding Author: Seth D. Pollak, PhD, University of Wisconsin, Department of Psychology and Waisman Center, 1500 Highland Ave, Madison, WI 53706 (spollak@wisc.edu).

Published Online: December 28, 2015. doi:10.1001/jamapediatrics.2015.3859. Conflict of Interest Disclosures: None reported

1. Hair NL, Hanson JL, Wolfe BL, Pollak SD. Association of child poverty, brain development, and academic achievement. JAMA Pediatr. 2015;169(9):822-829.

2. Pollak SD. Developmental psychopathology: recent advances and future challenges. World Psychiatry. 2015;14(3):262-269. 